\title{
PRACTICAL ASPECTS OF FULFILLING THE POST-INDUSTRIAL HERITAGE WITH INNOVATIVE MEDIA ART PRACTICES
}

\author{
Oleksandra Khalepa \\ Postgraduate Student, Junior Research Fellow at the Department of Design and Architecture, \\ Modern Art Research Institute of National Academy of Arts in Ukraine, Ukraine \\ e-mail: carbon.residence@gmail.com, orcid.org/0000-0002-6104-0132
}

\section{Summary}

The article deals with the aspects of filling the post-industrial heritage with innovative media art practices. On the example of actual foreign and domestic post-industrial locations, in particular, the activities of the experimental platform "Art Residence Carbon", the outlined aspects are practically realized and analyzed in this article. It is emphasized that the demand for creativity causes strong competition between the cities that attract and inspire creative people to create individual or collective art projects. Modern information technologies provide new opportunities for communication, contribute to the spread of the activist movement in the urban environment. In this context, it is noted that the role of artistic practices that are a way of translation of historical experience, fixation of the present and projection of the future is significantly increasing. Modern creative practices based on the latest digital technologies go beyond the established spaces of museums, galleries, etc., and are implemented on different platforms of Internet social platforms and urban spaces. It has been proved that the latest artistic practices unite the creators and viewers of artistic works into a single whole, level the boundary between the subject and the object, and provide limitless possibilities of expression and representation. These processes are a sign of democratic society as well as an important component of urban identity. It is shown that the activist movement involves not only professional artists, but also a wide range of diverse communities that strive for creative self-realization. Experimental approach is the basis for their search, artistic understanding of contemporary problems. As a result, it is emphasized that urban spaces become a kind of art laboratories for festivals, forums, discussions, social connections, and art projects. In many countries the defining functions of the information society (cultural and artistic, office, commercial, entertainment, etc.) have found the ability to deploy in large territories and have begun to develop devastated industrial spaces.

Keywords: media art, festival, post-industrial space.

DOI: https://doi.org/10.23856/4904

\section{Introduction}

Modern tendencies of social development in the XX and XXI centuries are characterized by comprehensive globalization, high level of technological development and mass spread of digital technologies, which determine new directions in all spheres of life. Culture is becoming a key element of social development, where creativity and the ability to change rapidly are increasingly valued at the post-industrial/information stage. For enterprising and highly adaptive people the opportunity to realize their own creative potential is an urgent necessity of life (Manovich, 2002).

Among urban areas suitable for realization of creative ideas are spaces of former industrial facilities because the post-industrial epoch deprived thousands of plants and 
factories of their original production function all over the world. In Ukraine, the abandoned industrial zones are a significant spatial reserve, relevant in situations of their use for creative purposes of communities. Among the most successful foreign examples Kunst-Werke (Berlin) Färgfabriken (Stockholm) DUMBO (New York) "Vinzavod", Design Factory "Flacon" and ARTPLAY (Moscow); "Weaver" (St. Petersburg), as well as domestic "Mystetskyi Arsenal", plant "Bolshevik", cultural space "Mill", art platform "G13", a new location platform cultural initiatives "isolation" (Donetsk-Kyiv), etc.

The radical change of the original functions of the former large-scale productions causes the problem of their integration into the cultural and artistic space of Ukraine. This long process is very complex and contradictory, as it requires fundamental changes in conditions of complete uncertainty. Each post-industrial location requires an individual approach, so the process of its modifications should be considered as a kind of art of integration, which can be implemented as a micro-urbanistic practice, as a means of representation, as a social design or as an artistic provocation. The leading characteristic of the art of integration is interdisciplinarity, which, on the one hand, generates complex problems and, on the other hand, enables the creation of new teams, effective partnerships and new artistic practices, the transition from the personal creation of an art object to collective creative activity involving artists as well as a wide range of different communities (Zheqian,2021).

In this context, the research of the processes of deployment of new artistic practices in post-industrial spaces of Ukraine, the role in these processes of the "synergistic" actor, whose activity provides the development and implementation of art projects, communication between all the actors in a particular location, is an important study task.

Analysis of recent studied and publications. In total, professional scientific research identified five main methods of integration of post-industrial buildings into the fabric of the modern city: restoration, regeneration, revitalization, museification and reconstruction, which are covered in the works of A. Remeshilo-Rybchynska, S. Shubovich, Y. Raninski, E. Mikhailovsky, S. Ivanov-Kostetsky and others.

On the global experience of the use of industrial heritage in the tourist and recreational activities focused the attention of V. Patsuka. Ukraine, according to the author, it is quite possible to implement a similar practice in industrial areas, to offer alternative sites to visit. Problems of industrial heritage studied by G. Denisik and V. Bondar, which recorded the first steps to rally the researchers of industrial culture in Ukraine, the growing number of descriptions of industrial buildings and structures as the basis for the classification, landscape mapping and development of projects for their rational use.

In the scientific studies of G. Agranovich, E. Matveev, Y. Lyubchenko, V. Zapariya the problems of reconstruction of abandoned industrial areas, proposals to improve their aesthetic properties as valuable urban areas and adaptation to modern requirements. Yu. Tyutyunnik substantiates the concept of the object of industrial culture, its significance and role in the formation of cultural landscapes, handles the basis of industrial design and aspects of constructive use of industrial objects.

All available suggestions for the further use of post-industrial objects concern only the work on their material "shell". Whereas the filling of industrial heritage spaces with new content, the integration of cultural practices into the environment of devastated industrial structures is beyond the scope of professional proceedings. The processes of filling the spaces of post-industrial objects with experimental creative practices significantly contribute to solving the problem of attracting the "old prom" to the context of modern urban life, potentially very suitable for the deployment of the game of art with social realities. It is integration processes as 
a component of the global cultural process that are significant factors in modifications of postindustrial spaces.

Article purpose: identify aspects of the reinterpretation of Ukraine's post-industrial heritage and explore tools for filling post-industrial locations with artistic practices.

\section{Presentation of the basic material}

In Ukraine, which for centuries was part of the Russian Empire, industrial progress began in the second half of the XIX century, after the abolition of serfdom (1861) and a series of bourgeois reforms in the 1860s-1970s. During the Soviet period, forced industrialization led to radical changes in the socio-economic processes in Ukraine. Extensive industrialization of Ukraine, as well as the entire Soviet Union, occurred by significantly limiting the population's vital needs and overstretching labor and industrial resources.

Ukrainian cities lost their self-government and independence in solving social and economic problems and became state property. The so-called "social city", i.e., cities attached to factories and plants, emerged in Ukraine as an outgrowth of the Soviet period. It was industry, and not the social factor (or life) of the people was considered the main urban factor. Plants and factories were built first, and residential settlements were built around them. The financing of the urban infrastructures that supported people's lives was based on the residual principle of capital investment in industry. The high rate of industrial construction had almost no effect on the welfare of the population, always suffering from domestic difficulties and lack of opportunities to fully meet their social and cultural needs.

On the day of industrialization centers of industrial production, had a large area, were formed mainly near large deposits of minerals, and were located mainly in separate locations on the periphery of cities. They had an extensive infrastructure and strong transit links with the settlements. Gradually, due to the extensive development of cities, the industrial areas ended up in the center of the city. After the collapse of the Soviet Union and the loss of economic ties, the industrial cities of Ukraine began to decline.

Today, the problem of filling abandoned post-industrial buildings is becoming more and more urgent with the shortage of sites for experimental research. With the emergence of innovative technologies such as the Internet, artificial intelligence, virtual and augmented reality, art is given new tools to explore the most pressing socially relevant topics.

In the spring of 2020, there was a crisis situation caused by the Coronavirus epidemic. This situation stimulated the search for new solutions for communication, interaction, events and in general stimulated the transition to digital technology. Cultural and artistic environment quickly enough responded and began to adapt to the new realities, although there are still discussions about the transition to the online mode of the sphere. In the new realities, quite a few cultural projects have emerged, especially in the field of digital art. In particular, as a result of online hackathon organized by HouseofEurope in April this year over 1100 representatives of culture, creative industries, and IT, 129 experts from Ukraine and the EU came up with 63 projects. The top three took home a cash prize for their project and eight others received grants for further support. This event gave quite a tangible boost to the implementation of innovative ideas in the new reality. In times of crisis, the cultural and artistic community received quite significant support from the Ukrainian Cultural Foundation, whose programs have supported more than 1,500 projects in the field of culture. On the whole such organizations as UCF, HouseofEurope stimulate the development of cultural and artistic sphere not only by means of material investments but also by teaching the basic skills of project management, increasing 
the competence of cultural workers themselves within the framework of a number of programs, envisaged parallel to the grant competitions.

The above-mentioned opportunities and the transition to online technology mode stimulated the emergence of new projects in the field of new media art. After all, digital space has become almost the most relevant solution in the conditions of lockdown and isolation. In particular, such festivals as PLAN B fest, Intercity, Respublika, House of Europe Festival, Creative Industries Forum and others have gone online, projects like Very Digital Residencies, Pandemic Media Space, V-Art, Artefact, American -arts-incubator 2020, Art Alley and Carbon Artlito and Carbon media art incubator appeared.

"Very Digital Residencies"-is rethinking the cultural heritage of Odessa and Kharkiv through new media and digital production. As a result, a creative team of 25 residents was selected to receive free curatorial support, materials, and access to workshops. During August-September, the residency program included more than 30 online sessions on digitalizing architectural objects, 3D modeling and design, and 10 workshop sessions, where the sculptures for the future exhibition were created. An exhibition of 13 objects from both cities was on view from Sept. 29 to Oct. 16.

PandemicMediaSpace is an international project of algorithmic composition and media art, created by the Ukrainian Association of Electroacoustic Music and the Polish Society of Electroacoustic Music. The project included 6 lectures on media art and presented a virtual space with the works of 8 artists, participants of PandemicMediaSpace, created with the support of the EU in the House of Europe program.

American-arts-incubator 2020 is a Ukrainian-American project that for the second year in a row has stimulated the creation of digital works. This year four projects were created using artificial intelligence, with 24 participants teamed up and presented online on May 14 to a wide audience. The project was a collaboration between the IZONE Foundation, the creative community IZONE, the U.S. Bureau of Education and Culture and the ZERO1 organization.

V-Art, is a platform for exhibition, sale, and presentation of DigitalArt works, aims to stimulate the market for digital art. The virtual platform was created by a cross-functional team combining over 60 years of experience in art, IT law, business, and augmented reality, with support from UCF and private investment. Today, the platform features more than 20 popular media artists.

"Art Alley" is a project to reimagine urban space. Through the digital art objects on the wall, visitors will learn about Ukrainian writers and musicians whose work reflects the unique cultural phenomena of Kyiv in different periods. The project was initiated by UrbanSpace 500 community, with the support of the Ukrainian Cultural Foundation.

ARTEFACT: CHOrnobyl-is virtual exhibition of Chernobyl, designed for viewing online and in VR-helmets, is presented at the eleventh MADATAC media art festival in Spain with the support of the Ukrainian Cultural Foundation. ARTEFACT: CHOrnobyl exhibits are very diverse. Among them are the works of both famous Ukrainian artists: the Chernobyl series of Maria Primachenko, who lived on the border with the Exclusion Zone, a series of prophetic paintings by Ivan Marchuk, 3D photobooth by Arsen Savadov, and the new names of Ukrainian media art.

More than 100 Ukrainian artists worked on the creation of ARTEFACT: CHOrnobyl, so that the whole world could see more than 50 new exhibits virtually and absolutely free from an ordinary computer. Because of the pandemic COVID-19 and quarantine the Spanish festival of media art MADATAC this year takes place online, so the exhibits are presented in a virtual space CHOrnobyl on the site-http://artefact.live/

CarbonArtlito and Carbonmediaartincubator - are projects of the public organization Carbon, in order to popularize and teach the art of new media in Ukraine. In the conditions of Coronacrisis the organization has gone online and today within the framework of the mentioned 
projects 45 events and more than 90 hours dedicated to the new media art have been held, 20 new media artists have been trained and a series of 10 works using such techniques as audiovisual performance, interactive installation, VJ, mapping, virtual and augmented reality, soundart, artificial intelligence, presented in a new revitalized location have been created. On November 21 Ukraine's first TD LivepatchingEvent was held, joined by 10 audiovisual artists and 6 musicians. As a result, more than 7:00 audio-visual content was created at OneLocation, in collaboration with digital art organizations TouchDesigner UA, CG EVENT Conference, Carbon and FrontPictures. During the work it became clear that the new reality requires innovative solutions that will ensure sustainable development of the project and community. That's why it was decided to create an online platform for the creation and presentation of digital art works.

The experiment conducted by the author on the site of Pavilion 13 of VDNH (location P13, "Coal Industry" of the National Complex “Expocenter of Ukraine") in 2017-2019, in accordance with the developed concept of adaptation for the art residence "Carbon", showed the promise of creating a creative space for the development of innovative artistic practices, self-realization of art communities and art education of visitors of different age groups.

As a result, a group of enthusiasts represented by curators and artists in the framework of the "Carbon" art residence acquired some experience, received the first cultural products, and demonstrated the ability to fill with content and modify the space of abandoned industrial sites. It has been established that the potential of artistic development of post-industrial locations is much greater than their adaptation for shopping and entertainment centers, offices, lofts. It is proved and confirmed by the results of the experiment that the leading strategy of transformation is the involvement of modern types of art with their inherent search for new forms of interaction between art and technology, creative formats, and collaborations between artists.

At the end of the first stage of the experiment, the leading direction of the Carbone art residence was recognized as media art, which corresponds to modern creative trends and emphasizes the imagery, uniqueness of the location. The building of pavilion №13 with its darkened and semi-darkened rooms of large size and high ceiling turned out to be potentially suitable for a media art laboratory that explores the artistic possibilities of the latest technologies, for exhibiting media works and products of various creative practices, for forming communities and educating event visitors (Nguyen et al., 2021).

Integration of post-industrial objects in the context of modern man's being is the art of synthesis of creative practices, carried out under the supervision of a curator, whose activities are aimed at establishing a creative interaction between artists, government, business, creative communities, and the like.

On the example of location P13 the peculiarities of curator's activity are defined, which consist in the successive deployment of works in several stages. On the first stage (if there is a conception of creation of a cell of contemporary art practices), specific types of practices congruent to the given location are defined. For this purpose, the curator's efforts are concentrated on the formation of a team of organizers and a creative community, which are ready to deal with the development of the location. Among the leading actions of the first stage is conducting search actions of different formats (festivals, workshops, laboratories, art residences). The result of the stage is the outlined directions of further work on the location, which are processed in the appropriate projects. For location P13 the leading direction was defined media art and experiments with the mixing of different types of contemporary art with appropriate educational support (Terracciano, 2021).

At the second stage a curatorial project with a clear definition of directions, formats of activity and necessary resources is developed. For location P13 it is a project of the art 
residence "Carbon" with a clearly defined scheme structured as several concentric circles, which consistently cover the core (the organizational and creative teams), the educational foundation (the second circle - laboratories of sound art, media art and performative practices). Integration of laboratories, their mutual reinforcement by activities, artistic products take place during festivals, workshops, Ukrainian and foreign residencies of "Carbon" (the third, external circle). This circle of public presentation of the created art products and - the final moment of local projects, which is an important component of the project "Carbon" as it allows to unite artists, to organize a creative leisure time for visitors.

According to the experimental period processed formats: festival ("Carbonarium", "CarbonMediaArtFest", "Chernobylingfestival_2018", "EthnoMusicFest", "ShantiSolsticeUkrainianCreativeWeek", "Tripoteca - PsychedelicFilm \& ArtFestivalatKiev", "KLF VJ Platform", "Trouble Fest", "Festival of Living Stories") lectures, discussions ("SMART. Media art lecture", lecture by Nikita Khudyakov "VR as an artistic tool", "PanelDiscussion: PerformanceArchitecture", discussion "Urbanism or Art?" a series of lectures in the framework of the project "The Alchemy of Motivation", "Digital parametric sculpture. Meetings at the exhibition Frontier"); master classes ("Wildvoice"/from Katya Barton, "Open Inclusive Jam"); contemporary art fair ("FirstFineArtsFair", "GIS-Fest Ukraine 2018"); residency ("Mariupol. Artistic Integration. "StarturGogolFest", "Re: main. Artresidence", "Media art residence"“"ArtefactChernobyl 33") exhibition ("Systemupdateavailable. Exhibition of media art.Daria Fez", "Exhibition ReWhale", "Fashion", "PunkFuturism", "Zabudova", "Hypostasis"); Forum (IV Forum of Creative Industries, "ZeroWasteHelden/Heroes"); Laboratories ("Theatrical practices and media art", performative laboratory "Body + City" "Laboratory of impersonation", "Borders of presence school of public performance with LiveArtLab", "Parametric architecture in the space of media installations", "Touchdesigner. Creating interactive art installations", "CarbonBaseLab", "CarbonMarketingLab", "CarbonMediaMode").

The Carbone Art Residence is an open structure for the newest initiatives, for participation in various external events (the fourth circle). Initiatives that come from outside, are analyzed by the organizational team, evaluated in the laboratories and, if they correspond to the directions of the residency, are integrated into the overall concept of "Carbon". The activity of the art residence "Carbon" unfolds according to the project, while the curator constantly monitors and analyzes all the events taking place at the location. The curatorial project must be open and sensitive to innovations.

As a result, ten international events were held at location P13, and twenty collaborative events between theater, contemporary, art, media, music, dance, and film artists, of which the vast majority were for the general public. The number of visitors is more than 15,000 . The realized events and activities helped to bring pavilion 13 of VDNH of Ukraine from the state of destruction to the mode of positive transformation, to the growth of public interest. As a result, for two years of the art residence "Carbon" activity the investment attractiveness of the location has increased significantly, which led to the initiative to re-equip the pavilion building to a modern art center (Kalashnikova, 2015).

At present, in the domestic space, modifications take place by creating local art spaces which are able to give an impulse for further development of abandoned spaces of the industrial era, while in European countries the issues of developing post-industrial areas are solved at the city and state level. In Ukraine, where the Revolution of Dignity (2013-2014) stimulated the emergence of numerous initiatives and new art centers, there are wide prospects for creative practices, the implementation of which will fully depend on the initiative of communities. There is a developed toolkit of interaction between the curator and the creative communities, aimed at the consolidation of local communities and the beginning of the processes of modification 
of abandoned objects of the "old prom". These processes in Ukraine are still experimental and require further research.

\section{Conclusions}

Post-industrial locations are very suitable for the realization of various new forms of contemporary art (media art, sound art, and performance, etc.) and their mixing. The most revealing is the festival format in which artistic practices interact most effectively, creating new creative products. Each time the post-industrial spaces, whose considerable size allows for different formats of events (from chamber to large-scale), are adapted to a particular event. However, for the realization of artistic projects, their large spaces require the involvement of a significant number of activities, financial and human resources.

Experimental studies have shown the high relevance of the problems of artistic redevelopment of post-industrial objects in Ukrainian cities and the willingness of communities to unite to solve them. Artistic direction of the modification of the former industrial spaces is very promising, as it meets the needs of modern society.

\section{References}

1. Manovich, L. (2002). The language of new media. MIT press.

2. Kalashnikova, A. A. (2015). Specialist media as the art field and the art market evolution reflector. Media/SPOLECZEŃSTWO, (5), 86-94.

3. Shkliarenko, Z. (2021). Performance Art: Interart, Intermediality and Interdisciplinarity. Naukovi zapysky NaUKMA. Istoriia i teoriia kultury [Scientific notes of NaUKMA. History and theory of culture], 4, 99-105.

4. Zheqian, D. L. (2021, January). The Visual Performance of Technology and Philosophy in" Contemporary Art". In Proceedings of the 2021 International Conference on Bioinformatics and Intelligent Computing (pp. 372-378).

5. Terracciano, A. (2021). Installation Art and the Issue of Gentrification: Exploring the Expanded Scenography of Zelige Door on Golborne Road. Konsthistorisk tidskrift/Journal of Art History, 90(2), 88-100.

6. Nguyen, B. V. D., Simeone, A. L., \& Vande Moere, A. (2021, March). Exploring an Architectural Framework for Human-Building Interaction via a Semi-Immersive Cross-Reality Methodology. In Proceedings of the 2021 ACM/IEEE International Conference on Human-Robot Interaction (pp. 252-261). 